\title{
INTRODUCTION OF CLUSTERIZATION PRINCIPLES IN THE SOLUTION OF PROBLEMS OF ENERGY EFFICIENCY AND ECOLOGICAL SAFETY OF THE EXISTENT BUILDING FUND
}

\author{
Serhii Kozhedub \\ Department of Architectural Constructions \\ Kyiv National University of Construction and Architecture \\ 31 Povitroflotsky ave., Kyiv, Ukraine, 03037 \\ Maksym Mykytas \\ Department of Architectural Constructions \\ Kyiv National University of Construction and Architecture \\ 31 Povitroflotsky ave., Kyiv, Ukraine, 03037 \\ Vitalii Ploskyi \\ Department of Architectural Constructions \\ Kyiv National University of Construction and Architecture \\ 31 Povitroflotsky ave., Kyiv, Ukraine, 03037
}

Bohdan Yeremenko

Department of Information Technology Design and Applied Mathematics Kyiv National University of Construction and Architecture

31 Povitroflotsky ave., Kyiv, Ukraine, 03037

\begin{abstract}
The aim of the work is to introduce clusterization principles in the solution of problems of energy efficiency and ecological safety of the existent building fund. The material of the research is the process of modeling of energetically effective architecture-building clusters. In this sense it is topical and expedient to elaborate technologies and schemes, able to support making decisions as to the formation of energetically effective architecture-building clusters. The main attention is paid to the solution of infrastructure problems of energy saving of the architecture-building branch, connected with the absence of universal models, distinct algorithms of the formation of energy efficiency clusters and reliable instruments of their activity optimization. But realization of advantages of energy efficiency clusters is possible only at introducing effective mechanisms of the formation of a structure, able to provide a result, optimal by an energy efficiency criterion. The work offers a scheme of the formation process of such structure. The synthesis of models of energetically effective architecture-building clusters is based on principles of the systemic construction of geometric models and provides the imitative modeling of different development scenarios of synthesized clusters. At this stage of the research a function of making decisions as to the real cluster formation is left for experts. But an algorithm of the synthesis of models provides the formation of a knowledge base that will be in further a base of an "internal model" of the intellectual system of supporting decisions making, elaborated for modeling cluster structures. The scientific novelty of the work is in the elaboration of theoretical bases of the technology of coordinating the structure with object properties.
\end{abstract}

Keywords: energy effective architecture-building cluster, energy- reconstruction, energy saving.

\section{Introduction}

The increase of energy efficiency of existent buildings and introduction of arrangements of energy saving, effective use of fuel-energetic resources, renewable energy sources and alternative fuel types are main priorities of any state. But as opposite to innovative solutions, introduced in new building or capital reconstruction of buildings, projects on local energy-reconstruction have a partial effect. Element by element energy-reconstruction, thermo-modernization or other arrangements of raising the energy efficiency to integral property complexes, 
placed at a separate territory, provided with autonomous engineer communications and energy supply, is not rational [1-3].

Such complexes as architecture-building clusters are complicated systems. System properties of cluster structures determine their additional potential, but often become a cause of inadequacy of developed models, for prospective planning and elaboration of a development strategy for clusters $[4,5]$.

Just that is why, the elaboration of methods and means of modeling clusters and scientific substantiation of choosing a structure of energetically effective architecture-building clusters remain an urgent scientific problem, which solution has an essential economic and scientific potential $[6,7]$.

\section{Aim of research}

The aim of the work is to introduce clusterization principles in the solution of problems of energy efficiency and ecological safety of the existent building fund by elaborating means and methods of the synthesis of models of energetically effective architecture-building clusters.

\section{Research materials and methods}

The classic approach to the synthesis (construction) of a model of any system provides the transfer from setting an "aim" to making "functions" and determining a "structure" that contains a final set of functional units and relations between them [8].

The material of the research is the process of modeling of energetically effective architecture-building clusters (EABC). An energetically effective architecture-building cluster consists of target objects and target organizations.

Target objects in this work are considered as complexes of buildings and edifices of different organizations that plan the formation of an energetically effective cluster on the base of the existent building fund by energy-reconstruction.

Such target objects are complicated systems that usually:

- Consist of buildings of different functional destinations;

- Buildings of one functional destination are erected in different times of different building materials and belong to different construction types;

- Compactly placed at limited territories;

- Function under different conditions.

The aim of clusterization (target function) of such objects is to decrease volumes of consumed energy at the expanse of saving energy resources. The target function may be achieved by optimizing the distribution of energy resources, thermo-modernization and other energetically effective arrangements, which realization is provided by different target organizations.

Thus, requirements to the structure of energetically effective architecture-building clusters depend on many factors. Additional conditions and limitations are set at forming a database and are usually connected with:

- Location at historical zones of cities, which are a historical heritage; planning.

- A schedule of functioning of bureaucratic institutions that influences building works

Earlier $[8,9]$ studied methods of forming a database of criteria, system signs, structural and functional connections between clusterization subjects, and also requirements that must be satisfied by energetically effective cluster structures of the building branch $[9,10]$ described in detail the process of elaborating mathematical instruments for modeling a cluster structure, optimal by energy efficiency parameters. This work is devoted to the transfer from the conceptual modeling to the elaboration of an intellectual system of supporting decisions making as to the formation of a real cluster structure.

Fig. 1 demonstrates the conceptual scheme of the elaboration of methodological principles of the introduction of energetically effective clusters' models in the building branch with a list of the model and methods, expedient to be used at different elaboration stages. At that the following abbreviations are accepted: GM - geometrical modeling; EE - expert evaluation; EM - evolution 
modeling; EMM - economic-mathematical modeling; NM - non-distinct models; SA - system analysis; SD - system dynamics; SC - system construction; ANN - artificial neuron networks.

The algorithm of EABC modeling (Fig. 1) is based on the methods of system geometric modeling. These methods form by the inductive-reductive scenario as a result of the counter comparison of data about subsystems of an object, the system of ideas about a modeling object and purpose-oriented construction of methods of geometric modeling (GM). The method and set of operations, used at realizing the algorithm are described in $[11,12]$.

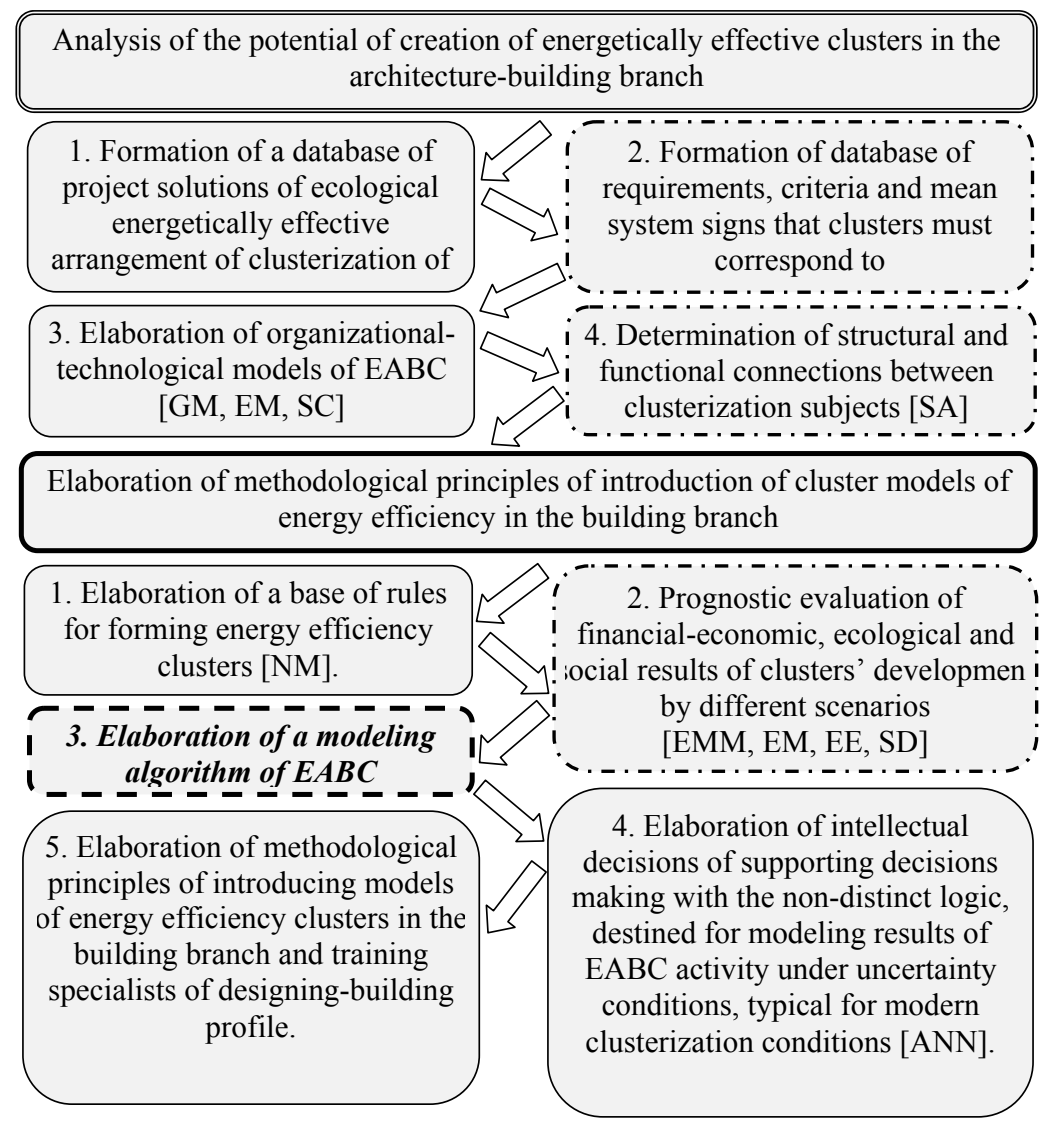

Fig. 1. Conceptual scheme of elaboration of methodological principles of introduction of energetically effective clusters' models in the building branch

Then there is offered the system of energetically effective architecture-building clusters' formation, according to which the cluster structure forms as a result of the criteria selection of candidates, able to provide the coordinated realization of set functions under given conditions, from the set.

\section{1. Calculating experiments}

The system construction (synthesis) and decisions as to organizational clusterization are offered to be realized based on the system analysis and expert evaluation of results of calculating experiments with energetically effective architecture-building clusters' models.

Fig. 2 demonstrates the scheme, according to which the synthesis algorithm of energetically effective architecture-building clusters' models is elaborated.

According to the scheme on Fig. 2, the synthesis of models is a result of comparing a set of practical problems on the one side and one of their solutions, on the other one. Sets of connections form as a result of realizing certain operations on geometric modeling methods [12].

Each synthesized EABC model undergoes calculating experiments for evaluating its activity results under different conditions by different scenarios. Calculating experiments are 
realized by scenarios of the inductive destination, elaborated by the principle "from practical requirements to a geometric model" [12]. Principles are based on including essential properties of form creation in the structure of the geometric modeling method, used for solving variation problems.

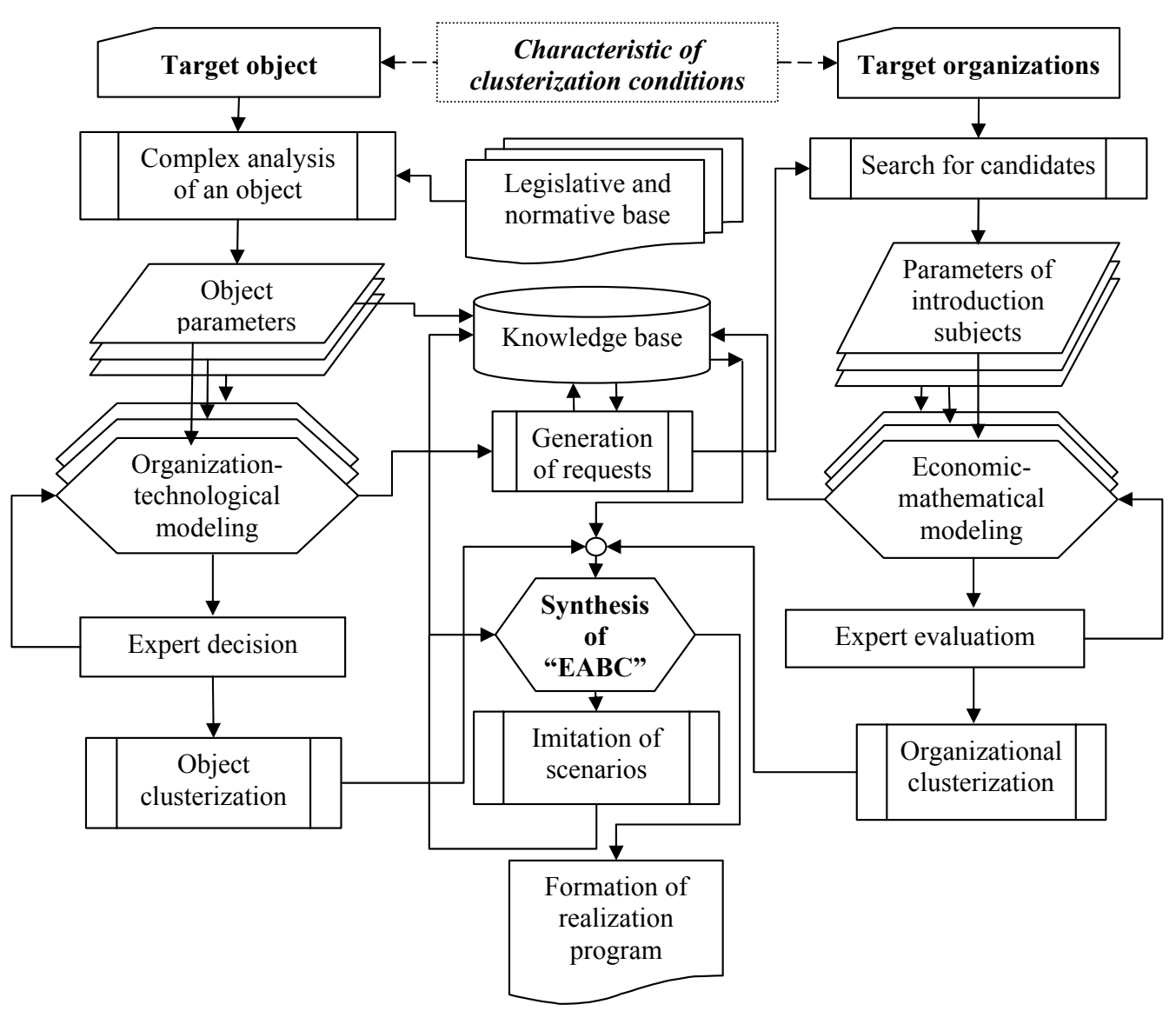

Fig. 2. Scheme of the formation process of energetically effective architecture-building clusters

At this approach clusters' models are synthesized as a result of the superposition of target objects and subjects of introduction, based on the criteria selection of introduction subjects, able to provide the coordinated realization of set functions under given conditions, from the set of target organizations.

The complex analysis of a target object, potential of creation of energetically effective clusters on its base, selection of candidates from the set of target organizations, set of probable changes in the external environment and influence degree of system properties on the adaptation mechanism of synthesized clusters, are determined and evaluated by experts.

A decision as to organizational clusterization at this stage is also accepted based on expert evaluations of parameters of introduction subjects and economic-mathematical modeling results. But the algorithm of EABC modeling, organization and realization of calculating experiments provide the formation of a knowledge base of the intellectual system of decisions making, elaborated for modeling cluster structures.

In further the generalized experience of experts is planned to be used for training artificial neuron networks, able to play the role of experts in such systems.

\section{Results}

Today such methods as stochastic limit analysis [1] and non-parametric one [2, 3] are widely used for determining cluster structures, most acceptable for combining. But none of them allows 
to determine a structure, most suitable for realizing the set aim under given conditions, unambiguously. It is connected with a fact that none of them solves the problem of multi-factor optimization and cannot prognosticate system properties of clusters.

$[5,6]$ describes properties of the cluster organization and management, but an analysis of system properties of clusters, necessary to be taken into account at elaborating models for prospective planning and development strategy of cluster structures, is absent.

Works [13, 14]:

- Present formalized, generalized and descriptive recommendations as to creation of territorial clusters for providing the competitiveness of the regional economy and sustainable regional development;

- Describe cluster strategies of state-private partnership, criteria and statements of the state policy of economy clusterization;

- Elaborate conceptual models of clusters of renewable energetics.

But these works don't present concrete formation aspects and optimization instruments of cluster structures sufficiently.

The expected practical importance of results of this study is in:

1) the use of geometric modeling methods gives a possibility to automate the process of purpose-oriented synthesis of cluster models;

2) the analysis of results of calculating experiments with synthesized models provides the scientifically grounded support of making decisions as to forming real clusters taking into account peculiarities of target objects and characteristics of clusterization conditions;

3 ) based on imitation modeling of the system of key parameters of energy efficiency, there appears a possibility to optimize the use of fuel-energetic resources, renewable energy sources, alternative fuel types and to manage the flow distribution of combined resources of a cluster.

\section{Conclusions}

1. For realizing the conception of creation of the energetically effective, eco-safe, comfort architecture environment, there has been formed the conceptual scheme of elaboration of methodological principles of introducing models of energetically effective architecture-building clusters. The elaborated principles may be used at realizing arrangements, directed on reducing thermal losses of heat-supplying systems by their optimization at reconstruction.

2. The methodology of introducing models of cluster structures in the building branch needs elaborating program means for realizing the purpose-oriented synthesis of models. The work of the algorithm, elaborated for synthesizing models of energetically effective architecture-building clusters, is offered to be based on geometric modeling methods.

3. At this stage of the research a function of making decisions as to the real cluster formation is left for experts. But the algorithm of EABC modeling provides the formation of the knowledge base that will be in further a base of an "internal model" of the intellectual system of supporting making decisions with the non-distinct logic.

\section{References}

[1] Lundgren, T., Marklund, P.-O., Zhang, S. (2016). Industrial energy demand and energy efficiency - Evidence from Sweden. Resource and Energy Economics, 43, 130-152. doi: http://doi.org/10.1016/ j.reseneeco.2016.01.003

[2] Shi, G.-M., Bi, J., Wang, J.-N. (2010). Chinese regional industrial energy efficiency evaluation based on a DEA model of fixing non-energy inputs. Energy Policy, 38 (10), 6172-6179. doi: http://doi.org/ 10.1016/j.enpol.2010.06.003

[3] Özkara, Y., Atak, M. (2015). Regional total-factor energy efficiency and electricity saving potential of manufacturing industry in Turkey. Energy, 93, 495-510. doi: http://doi.org/10.1016/j.energy. 2015.09.036 
[4] Sölvell, Ö., Lindqvist, G., Ketels, C. (2003). The Cluster Initiative Greenbook. Stockholm: Ivory Tower, 92

[5] The Role of Clusters in Smart Specialisation Strategies (2013). Luxembourg: Publications Office of the European Union, 59.

[6] Smart guide to cluster policy (2016). Belgium, 60.

[7] Mykytas, M. V., Ploskyi, V. O. (2017). Stalyi rozvytok mist: stan doslidzhen, mizhnarodnyi ta ukrainskyi dosvid. Enerhoefektyvnist v budivnytstvi ta arkhitekturi, 9, 168-173.

[8] Mykytas, M. V., Ploskyi, V. O., Kozhedub, S. A. (2018). Doslidzhennia systemnykh oznak enerhoefektyvnykh klasternykh orhanizatsiinykh struktur arkhitekturno-budivelnoi haluzi. Upravlinnia rozvytkom skladnykh system, 35, 68-75.

[9] Mykytas, M., Terenchuk, S., Zhuravska, N. (2018). Models, Methods and Tools of Optimizing Costs for Development of Clusterized Organizational Structures in Construction Industry. International Journal of Engineering \& Technology, 7 (3.2), 250. doi: http://doi.org/10.14419/ijet.v7i3.2.14414

[10] Kulikov, P., Mykytas, M., Terenchuk, S., Chupryna, Y. (2018). Development of a methodology for creating adaptive energy efficiency clusters of the architecture and construction industry. Technology Audit and Production Reserves, 6 (5 (44)), 11-16. doi: http://doi.org/10.15587/2312-8372.2018.150879

[11] Klir, Dzh. (1990). Sistemologiya. Avtomatizatsiya resheniya sistemnykh zadach. Moscow: Radio i svyaz', 544.

[12] Ploskiy, V. A. (1996). Operatsii na mnozhestve metodov geometricheskogo modelirovaniya kak element ikh sistemnogo issledovaniya. Prikladnaya geometriya i inzhenernaya grafika, 60, 79-83.

[13] Prokip, A. V., Dudiuk, V. S., Kolisnyk, R. B. (2015). Orhanizatsiini ta ekoloho-ekonomichni zasady vykorystannia vidnovliuvanykh enerhoresursiv. Lviv: ZUKTs, 338.

[14] Mamonova, V. V., Kuts, Yu. O., Makarenko, O. M. et. al. (2013). Formuvannia terytorialnykh klasteriv yak instrumentu rehionalnoho rozvytku. Kyiv: NADU, 36. 